\title{
Modeling of processes and technologies of the Concentrating Raspadskaya Factory for assessing the impact of dilution of raw coal on the technological performance of enrichment products
}

\author{
Vladimir Udovitsky ${ }^{1, *}$, Vladimir Kandinsky ${ }^{1}$, Artyom Begunov ${ }^{1}$ and Larisa Plotnikova ${ }^{1}$ \\ ${ }^{1}$ T.F. Gorbachev Kuzbass State Technical University, Department of mineral resources processing, \\ 650000 Kemerovo, 28 Vesennya st., Russian Federation
}

\begin{abstract}
The paper presents a brief literature review on the impact of the dilution of mined coal from complex structural deposits on losses during selective and gross excavation of layers. The increase in dilution leads to a reduction in coal losses during mining. The effect of dilution on the loss of coal with beneficiation was established. A method is proposed for calculating sieve and fractional composition of coal depending on the ash content of the diluted coal using the example of sample No. 9 of the reservoir developed at Mine cut Raspadsky CJSC. The effect of ash content of diluted coal, enriched according to the technology of the Raspadskaya Processing Plant, is shown on the technological indicators of the enrichment products in the practical balance. It has been established by computational experiments that when the ash content of ordinary coal changes from $17.8 \%$ to $25.2 \%$ and the condition that the concentrate should have an ash content in the practical balance of not more than $6.8 \%$, its output decreases from $84.4 \%$ to $73.3 \%$, i.e. $11.1 \%$ of concentrate is irretrievably lost with rock shipped to the dump; the ash content of the rock decreases, which can lead to its ignition at the dump. An increase in rock yield, in turn, will lead to additional transport costs and even greater environmental damage.
\end{abstract}

\section{Introduction}

Dilution - loss of mineral quality during the mining process. It is expressed in a decrease in the content of the useful component or the useful component in the extracted mineral in comparison with their content in the mineral array (balance reserves). When assessing the quality of combustible minerals (coal, shale), the indicator is used - the ash content of coal (inorganic mass content, expressed as a percentage of the initial mass of the product). Dilution is the main feature characterizing the quality of the minerals mined; closely related

\footnotetext{
* Corresponding author: uvi@,kuzstu.ru
} 
to the loss of minerals. Usually, the greater the dilution, the smaller the loss during production [1].

The publication [2] shows the options for the dilution of coal mined: in the case of gross excavation, due to intra-layer rock layers; with selective - due to mining of coal plots by contact with the roof and soil. Previously, the authors of the publication [3] also indicated that when developing complex structural deposits, it is almost impossible to exclude losses and dilution of the mineral. This study shows the effect of the dilution of mined coal on the technological performance of products obtained at the processing plants (for example, Raspadskaya Processing Plant).

\section{Materials and Methods}

\subsection{Initial data}

The initial data for the calculation of technological processes and enrichment schemes are the sieve and fractional compositions of the sample number 9 of the layer of JSC Mine cut Raspadsky (Figure 1).

\begin{tabular}{|c|c|c|c|c|c|c|c|c|c|c|c|c|c|}
\hline \multirow{3}{*}{$\begin{array}{l}\text { Size of the } \\
\text { class, mm }\end{array}$} & \multirow{2}{*}{\multicolumn{2}{|c|}{ Sitovyj composition }} & \multicolumn{10}{|c|}{ Fractional composition } & \multirow{3}{*}{$\mathrm{T}, \%$} \\
\hline & & & \multicolumn{2}{|c|}{$1.3-1.4$} & \multicolumn{2}{|c|}{$1.4-1.5$} & \multicolumn{2}{|c|}{$1.5-1.6$} & \multicolumn{2}{|c|}{$1.6-1.8$} & \multicolumn{2}{|c|}{$>1.8$} & \\
\hline & $\gamma, \%$ & $\mathrm{~A}^{\mathrm{d}}, \%$ & $\gamma, \%$ & $A^{d}, \%$ & $\gamma, \%$ & $\mathrm{~A}^{\mathrm{d}}, \%$ & $\gamma, \%$ & $\mathrm{~A}^{\mathrm{d}}, \%$ & $\gamma, \%$ & $\mathrm{~A}^{\mathrm{d}}, \%$ & $\gamma, \%$ & $\mathrm{~A}^{\mathrm{d}}, \%$ & \\
\hline $13-150$ & 33,20 & 36,09 & 17,86 & 5,70 & 1,49 & 18,80 & 0,73 & 31,20 & 1,39 & 46,20 & 11,72 & 83,70 & 9,89 \\
\hline $0.13-1.3$ & 16,70 & 5,80 & & & & & & & & & & & \\
\hline $0-0.13$ & 3,60 & 19,90 & & & & & & & & & & & \\
\hline Total: & 100,00 & 17,84 & & & & & & & & & & & \\
\hline
\end{tabular}

Fig 1. Sieve and fractional formulations of sample No. 9 of the reservoir being developed at Mine cut Raspadsky CJSC.

The last column of table 1 shows the values of enrichment, $\mathrm{T}$ for machine classes, calculated according to the method GOST 10100-84. Obviously, the enrichment class more than $13 \mathrm{~mm}$ "difficult", and 1-13 mm - "easy".

The density of rocks of the Kuznetsk suite according to [3] is presented in table 1.

Table 1. The density of the rocks of the Kuznetsk suite

\begin{tabular}{|c|c|}
\hline Species: & Density, $\mathrm{g} / \mathrm{cm}^{3}$ \\
\hline shale & $2.58 \div 2.62$ \\
\hline mudstones & $2.62 \div 2.65$ \\
\hline sandstones & $2.65 \div 2.75$ \\
\hline Natural burnt rocks & $2.2 \div 2.6$ \\
\hline
\end{tabular}

In the development of reservoir deposits by selective or gross methods, the amount of crushed rock falling into the coal seam varies from 0 to $90 \%$. The resulting mixture is recycled to factories or concentrators.

In this work, the technological enrichment scheme of the Raspadskaya Processing Plant is adopted (Figure 1). 


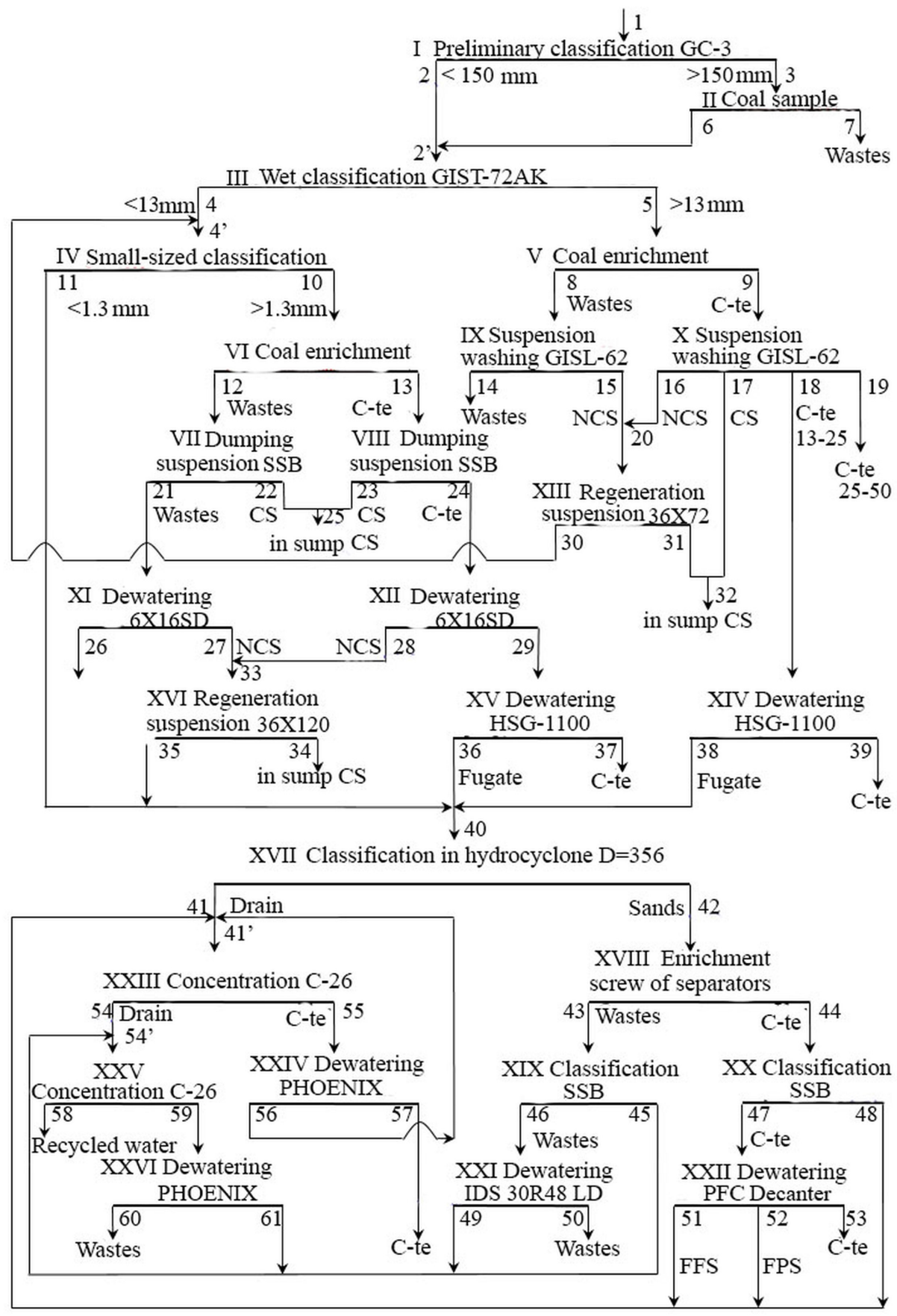

Fig.2. Technological scheme of enrichment of ordinary coal at the Raspadskaya Processing Plant.

The calculation of the yields and ash content of enrichment products in gravitational vehicles is performed according to known formulas, published in $[4,5,6,7]$ :

$$
\gamma=\sum_{i=1}^{n} \gamma_{i} \cdot F\left(x_{i}\right)
$$




$$
A^{d}=\frac{\sum_{i=1}^{n} \gamma_{i} \cdot A_{i}^{d} \cdot F\left(x_{i}\right)}{\sum_{i=1}^{n} \gamma_{i} \cdot F\left(x_{i}\right)}
$$

where $n$ is the number of fractions; $F\left(x_{i}\right)$ - is the value of the Gauss probability integral (the calculation of the integral values for Excel and TurboPascal is described in detail in $[6,7])$; $\gamma_{i}, A^{d}{ }_{i}$ - yield and ash fraction; $x_{i}$ - is the deviation of the average density of the $\rho_{c p}$ fractions from the planned separation density $\rho_{p}$ :

$$
x= \pm\left(\rho_{p}-\rho_{c p}\right) / E_{p} \cdot 0.675
$$

the plus sign in the formula (3) is taken in determining the extraction of fractions in concentrate and the minus sign in waste.

\subsection{Mathematical models}

Dilution of the coal produced occurs due to the ingress of rock into it, the density of which varies within $2.2 \div 2.75 \mathrm{~g} / \mathrm{cm} 3$ (Table 2). Consequently, it can be assumed with sufficient confidence that during gravitational enrichment processes of ordinary coal, the rock will turn into a fraction with a density of more than $1.8 \mathrm{~g} / \mathrm{cm}^{3}$.

Depending on the amount of this rock, the sieve and fractional compositions of raw coal change, affecting the processing technology, as well as quantitative and qualitative indicators of the coal products produced. The mathematical model for calculating sieve and fractional compositions of diluted coal is represented by formulas (4) - (7):

Reservoir share in charge

$\gamma_{p o r}-$ amount of collapsed rock, $\%$

$$
\gamma_{\text {plast }}=100-\gamma_{\text {por }}, \%
$$

Output of rock falling into $i$ - machine class

$$
V_{i} \text { por }=D_{i} \cdot \gamma_{\text {por }} / 100, \% \text {; }
$$

$D_{i}$ - is part of the collapsed rock of its total number $\gamma_{p o r}$, falling from into $i$ - machine class.

Output and ash content of the class, taking into account the breed that fell into it

$$
\begin{gathered}
\gamma_{i}=\gamma_{i} \text { sit } \cdot \gamma_{\text {plast }} / 100+V_{i} \text { por }, \% ; \\
A^{d}{ }_{i}=\left(\gamma_{i} \text { sit } \cdot \gamma_{\text {plast }} \cdot A^{d_{i}} \text { sit }+V_{i} \text { por } \cdot A^{d}{ }_{i} \text { por }\right) / \gamma_{i}, \%,
\end{gathered}
$$

$\gamma_{i}$ sit, $A^{d}{ }_{i}$ sit -yield and ash content $i$ of machine class by sieve composition, $A^{d}{ }_{i}$ por $=92 \div 96 \%$ - ash content of the collapsed rock.

According to the publications $[4,5,6]$, as well as the current regulatory document VNTP 3-92 in the Russian Federation, the clogging of coal enrichment products is accepted in heavy-medium separators for a particle size of $13-150 \mathrm{~mm}$

in two-product heavy hydrocyclones

$$
E_{p}=0.015 \cdot \rho_{p}+0.02, \mathrm{~g} / \mathrm{cm}^{3}
$$

$$
E_{p}=0.03 \cdot \rho_{p}-0.015, \mathrm{~g} / \mathrm{cm}^{3} .
$$

The calculation of the scheme (Figure 1) was performed using methods that allow to determine the separation density at which the highest yield of the total concentrate of the required ash content is achieved. Techniques are published in $[8,9,10]$.

Assumptions adopted in the calculation of indicators of enrichment end products:

- the ash content of the total concentrate should be constant and equal to $6.8 \%$ at its highest yield;

- Dilution leads to an increase in the ash content of the reservoir (row "Total" of Table 1) from 17.8 to $25.2 \%$ (Table 3) with intermediate values: 19.1, 20.5, 22.7, $23.9 \%$ (Figure 4). 


\section{Results and Discussion}

Using a specially developed program in TurboPascal to calculate the Raspadskaya Processing Plant presented in Figure 1, the results of the practical balance of the enrichment products for five dilution options for sample No. 9 of the reservoir developed at Razrez Raspadsky CJSC are obtained.

The program calculates separation densities in a heavy-medium separator (operation $\mathrm{V}$ on the diagram) and a heavy-medium hydrocyclone (operation VI) to achieve the maximum yield of the total concentrate.

The total concentrate consists of dehydrated concentrates of a heavy-medium separator with a particle size of 25-150 mm (operation X, product 19) and a particle size of 13-25 $\mathrm{mm}$ (operation XIV, product 39); screw separator concentrate after dewatering (operation XXII, product 53) and press filter cake (operation XXIV, product 57).

The practical balance is calculated for the ash content of the total concentrate equal to $6.8 \%$ in all options for dilution of sample No. 9.

Figure 3 shows the final fragment of the program, showing the practical balance for sample No. 9 with an ash content of $17.8 \%$. The initial data for the calculation is taken from Table 1.

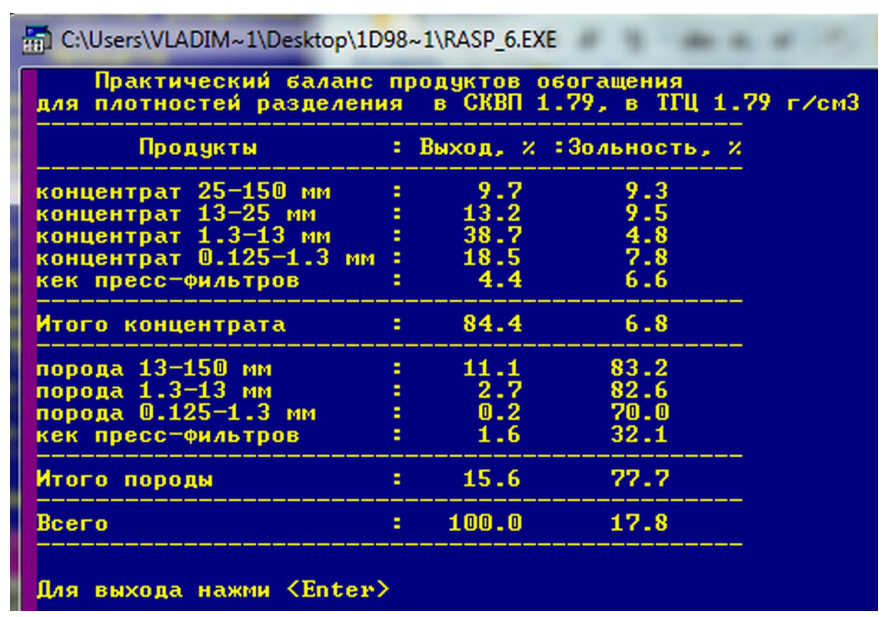

Fig. 3. A fragment of the program with a practical balance of enrichment products, calculated for a sample of ash content of $17.8 \%$

Using the formulas (4) - (7), the sieve and fractional compositions of sample No. 9 diluted from ash content of $17.8 \%$ (table 1 ) to $25.2 \%$ (table 3 ) were calculated on a computer.

\begin{tabular}{|c|c|c|c|c|c|c|c|c|c|c|c|c|c|}
\hline \multirow{2}{*}{$\begin{array}{l}\text { Size of the } \\
\text { class, mm }\end{array}$} & \multirow{2}{*}{\multicolumn{2}{|c|}{ Sitovyj composition }} & \multicolumn{10}{|c|}{ Fractional composition } & \multirow[b]{2}{*}{$\mathrm{T}, \%$} \\
\hline & & & \multicolumn{2}{|c|}{$1.3-1.4$} & \multicolumn{2}{|c|}{$1.4-1.5$} & \multicolumn{2}{|c|}{$1.5-1.6$} & \multicolumn{2}{|c|}{$1.6-1.8$} & \multicolumn{2}{|c|}{$>1.8$} & \\
\hline $13-150$ & 33,90 & 42,61 & 16,17 & 5,70 & 1,36 & 18,80 & 0,68 & 31,20 & 1,25 & 46,20 & 14,44 & 86,40 & 9,93 \\
\hline $0.13-1.3$ & 16,50 & 13,50 & & & & & & & & & & & \\
\hline $0-0.13$ & 3,70 & 29,40 & & & & & & & & & & & \\
\hline Total: & 100,00 & 25,16 & & & & & & & & & & & \\
\hline
\end{tabular}

Fig. 4. Sieve and fractional compositions of sample No. 9 of the reservoir being developed at Mining cut Raspadsky CJSC; dilution to $25.2 \%$

Tables 1 and Figure 4 draws attention to the enrichment index $\mathrm{T}$, the value of which practically does not change as a result of dilution. 
For the sieve and fractional compositions (Table 3), a practical balance of enrichment products was also calculated (Figure 5).

\begin{tabular}{|c|c|c|c|}
\hline \multicolumn{4}{|c|}{ 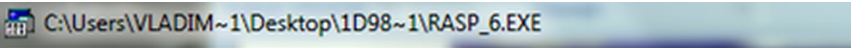 } \\
\hline $\begin{array}{c}\text { Практический баланс } \\
\text { для плотностей разделени }\end{array}$ & $\begin{array}{l}\text { продуктов } \\
\text { 4 в СКВП }\end{array}$ & $\begin{array}{l}\text { 06огацения } \\
1.51 \text {, в ТГЦ } 1.48\end{array}$ & $\mathrm{r} / \mathrm{cm} 3$ \\
\hline Продукты & : Выход, \% & : Зольность, \% & \\
\hline $\begin{array}{l}\text { концентрат } 25-150 \mathrm{mM} \\
\text { концентрат } 13-25 \mathrm{mM} \\
\text { концентрат } 1.3-13 \mathrm{MM} \\
\text { концентрат } 0.125-1.3 \mathrm{~mm} \\
\text { кек пресс-фильтров }\end{array}$ & $\begin{array}{r}7 . ? \\
10.7 \\
34.5 \\
16.3 \\
4.2\end{array}$ & $\begin{array}{r}7.4 \\
7.6 \\
4.8 \\
7.8 \\
17.0\end{array}$ & \\
\hline Итого концентрата & 73.3 & 6.8 & \\
\hline $\begin{array}{l}\text { порода } 13-150 \mathrm{~mm} \\
\text { порода } 1.3-13 \mathrm{~mm} \\
\text { порода } 0.125-1.3 \mathrm{~mm} \\
\text { кек пресс-фильтров }\end{array}$ & $\begin{array}{r}16.3 \\
6.6 \\
1.7 \\
2.1\end{array}$ & $\begin{array}{l}77.0 \\
84.3 \\
70.0 \\
42.1\end{array}$ & \\
\hline Итого породы & 26.7 & 25.6 & \\
\hline Bcero & 100.0 & 25.2 & \\
\hline
\end{tabular}

Fig. 5. Fragment of the program with a practical balance of enrichment products calculated for an ash content of $25.2 \%$

When the sample was diluted, the yield of total concentrate decreased from $84.4 \%$ (Figure 2) to $73.3 \%$ (Figure 3), i.e. by $11.1 \%$.

For intermediate values of ash content of diluted sample No. 9, similar calculations were performed. The results obtained are placed in table 2 .

Table 2. The effect of dilution on technological indicators concentrate and waste.

\begin{tabular}{|c|c|c|c|c|}
\hline \multirow{2}{*}{$\begin{array}{l}\text { Ash content } \\
\text { diluted } \\
\text { samples, \% }\end{array}$} & \multicolumn{2}{|c|}{ Concentrate } & \multicolumn{2}{|c|}{ Waste } \\
\hline & $\begin{array}{c}\text { Yield, } \\
\%\end{array}$ & $\begin{array}{c}\text { Ash content, } \\
\%\end{array}$ & $\begin{array}{c}\text { Yield, } \\
\%\end{array}$ & $\begin{array}{c}\text { Ash content, } \\
\%\end{array}$ \\
\hline 17.8 & 84.4 & 6.8 & 15.6 & 77.7 \\
\hline 19.1 & 82.8 & 6.8 & 17.2 & 77.8 \\
\hline 20.5 & 80.8 & 6.8 & 19.2 & 77.7 \\
\hline 22.7 & 77.6 & 6.8 & 22.4 & 77.4 \\
\hline 23.9 & 75.7 & 6.8 & 24.3 & 77.0 \\
\hline 25.2 & 73.3 & 6.8 & 26.7 & 75.6 \\
\hline
\end{tabular}

\section{Conclusion}

Computational experiments have established:

1. An increase in the dilution of coal mined from $17.8 \%$ to $25.2 \%$ reduces losses during selective and gross excavation.

2. In case of fulfillment of contractual obligations by the concentrating plant to observe the constancy of the ash content of the concentrate being shipped (in our example no more than $6.8 \%$ ):

- increases the loss of concentrate output from the beneficiation plant from $84.4 . \%$ to $73.3 \%$, i.e. by $11.1 \%$;

- increases the rock yield from $15.6 \%$ to $26.7 \%$, i.e. $11.1 \%$ of the ash content of $6.8 \%$ will permanently go to the dump together with the rock;

- an increase in breeding yield will lead to additional transport costs associated with its transportation; 
- A decrease in the ash content of the rock falling into the dump may lead to its ignition and additional environmental damage.

\section{References}

1. Mineral dilution. URL: http://www.mining-enc.ru/r/razubozhivanie/

2. V.L. Gavrilov, S.A. Ermakov, D.V. Hosoev, GIAB, 11 (2010)

3. S.A. Ermakov, D.V. Hosoev, V.L. Gavrilov, E.A. Hojutanov, Gornaya promyshlennost, $6(2012)$

4. K. Tromp, Neue Wege fur die Beuerteilung der Aufbereitung von Steinkohlen (Gluckauf, Berlin, 1937)

5. A. Terra, Revue de lindustrue minerale (Pellette, Paris, 1939)

6. A. Terra, Sens de la courbe de partage anamorphosee et de lecart probable dans le controle des lavoirs (Revue de lindustrue minerale, Paris, 1955)

7. J. Winckler, G. Mustafi, Mining Challenges of the 21st Century (APH Publishing Corp., New Delhi, 2000)

8. V.I. Chudovitsky, XX International Mineral Processing Congress (DTAH, Aachen, 1997)

9. V. Udovitsky, V. Kandinsky, A. Begunov, E3S Web Conf., 15, (2017)

10. V. Udovitsky, V. Kandinsky, E3S Web Conf., 41, 01011 (2018) 